\title{
Pesticide Contamination Monitored by Passive Sampling in Environmental Water of Japanese Coral Island
}

\author{
Yutaka Tashiro', Yutaka Kameda ${ }^{2}$ \\ ${ }^{1}$ Faculty of International studies, Meio University, Nago, Okinawa, Japan \\ ${ }^{2}$ Faculty of Engineering, Chiba Institute of Technology, Narashino, Chiba, Japan
}

Email address:

tashiro@meio-u.ac.jp (Y. Tashiro)

\section{To cite this article:}

Yutaka Tashiro, Yutaka Kameda. Pesticide Contamination Monitored by Passive Sampling in Environmental Water of Japanese Coral Island. Journal of Water Resources and Ocean Science. Vol. 4, No. 2, 2015, pp. 39-43. doi: 10.11648/j.wros.20150402.12

\begin{abstract}
The pesticide contaminations in the water of rivers and an estuary of a Japanese coral island with unique ecosystems in enclosed moats and on fringing reefs were analyzed by means of passive sampling. Samplers were deployed in the rivers and estuary for each 2 weeks of August through December of 2013 and of February of 2014. One to 12 kinds of pesticides were detected from all the samplers at the river sites with the maximum amount of $260 \mathrm{ng}^{-1} \mathrm{da}^{-1}$ per sampler for EPN. The detected compounds and their amounts fluctuated widely at each sampling occasion. The analyses of the grab water samples detected much less compounds in comparison with the passive samples from the same sites. The time weighted average (TWA) concentrations of these pesticides are estimated as several micrograms per litter in the river waters. Further, $0.1 \mathrm{ng}^{-1 a y^{-1}}$ of procymidone was also detected from a sampler in the middle of the estuary where the river water is largely diluted with seawater. This amount of pesticide corresponds to a TWA concentration in the estuary water with the order of several ng $\mathrm{L}^{-1}$. Considerable discharges of chemicals into coastal water by intensive agricultural practices such as flower cultivations on the island is concerned.
\end{abstract}

Keywords: Coastal Environment, Coral Reef, Agriculture, Pesticide, Water Pollution, Passive Sampling

\section{Introduction}

Coral reefs are one of the most biologically productive and diverse ecosystems in the world. Although they are important as the basis of marine fisheries and tourism in tropical and subtropical regions, they have been damaged by human activities, such as reclamations and water pollutions. Japanese Southwest Islands, which are composed of about 200 islands between Japanese main islands and Taiwan including the largest Okinawa Island $\left(1,204 \mathrm{~km}^{2}\right)$, are surrounded by fringing reefs with coral ecosystems of prominent biodiversity [1]. As agriculture is one of the important industries on these islands, farms occupy a significant part of the land-uses there. Annual rainfall on these islands is approximately $2,000 \mathrm{~mm}$, and a considerable part of the rain water is drained through the surface soil of the farms into coastal seawater as surface water and shallow groundwater. Although sugar cane has been traditionally cultivated on the majority of these farms, vegetable, fruit and flower cultivations are also increasing in recent years. As residual pesticides are generally controlled only in edible products, farmers tend to use a large amount of pesticides especially for the cultivation of flowers to avoid any pests which may damage their appearance. Previous researches on one of these islands revealed that more than ten times larger amount of pesticides are used for flowers in comparison with those for vegetables [2]. Although these backgrounds have been arising concerns about the impacts of pesticides discharged into coastal seawater on the coral ecosystems, information about the pollution level of water environment by chemicals in these islands is limited [3-6].

As the quantity and quality of agricultural drainages often change drastically with rainfall events and those of coastal seawaters with tide, grab sampling at river and/or sea is not always efficient to figure out the state of pollution. Also meaningful comparison between samples with the concentrations near the detection limit tends to need intensive laboratory works. The passive samplers such as Chemcatchers $^{\mathbb{R}}$ [7] are based on the diffusion of target compounds through a membrane and the subsequent 
accumulation in a solid phase extraction disk. As the amount of the accumulated compounds reflect their time weighted average (TWA) concentrations in the environmental water where a sampler was deployed, these samplers are widely used for the assessments of pollutants with low and/or fluctuating concentrations in aquatic environment [8-11]. The present study revealed actual occurrences of pesticides in the rivers and coastal seawater of the Okinawa Island, the largest and the most populated one of these islands, by means of passive sampling.

\section{Materials and Methods}

\subsection{Sampling Sites}

Six sampling sites (A-F in Fig.1) were established on the Okinawa Island. Sites A and B were in the rivers of the northern area of the island, while sites $C$ and $D$ were in the central area. These sites were selected to represent the rivers which are located in the typical agricultural areas of the island and which receive the drainages from flower (chrysanthemums) farms. The distance along the river from each site to the coast is also shown in Fig.1. As these sites were on a small island, all of them were close to the coasts and thus to the fringing reef ecosystems around the island. Sites E and $F$ were located at the inner part and at the middle of an estuary which is downstream of site $\mathrm{B}$, respectively.

\subsection{Target Compounds}

Table 1 shows the 28 pesticide which were selected as the targets of the monitoring in the present study. They were consumed with large quantities in Okinawa Prefecture, Japan [12], and are the compounds which can be analyzed in aquatic samples by means of solid phase extractions and quantification with a gas chromatograph mass spectrometer [13].

\subsection{Sampling Procedures and Chemical Analyses}

The passive samplers which were consisted of a Empore ${ }^{\circledR}$ styrenedivinylbenzene (SDB-XC) disk (47 mm diameter, 3M) as a receiving phase fitted with a diffusion limiting membrane of low density polyethylene (Omnipore ${ }^{\circledR} 0.2 \mu \mathrm{m}$ pore size, 47 $\mathrm{mm}$ diameter, Merck) were used for sampling. Chemcatchers ${ }^{\circledR}$ were purchased from 3M Japan Ltd. (Tokyo, Japan), and the samplers with more compact design (Fig.2), which were similar to those used by Vermeirssen et al. [14] in the sense that they held the disk and membrane between the plates, were fabricated for the use in shallow rivers.

Samplers were deployed at sites A-D for each 2 weeks of August through December of 2013, and at sites E and F for 2 weeks of February of 2014. Afterwards they were brought back to the laboratory for disassembly. The SDB-XC disk was taken off the sampler body, dried under vacuum using a vacuum manifold for about $20 \mathrm{~min}$, and subsequently eluted twice with $5 \mathrm{~mL}$ acetone with $5 \mathrm{~min}$ ultrasonic treatment. The eluate was evaporated to $0.2 \mathrm{ml}$ under a gentle stream of nitrogen and analyzed for pesticides using a GC-17A gas chromatograph (Shimadzu Corp., Kyoto, Japan) coupled to a QP5050 mass spectrometer (Shimadzu Corp., Kyoto, Japan) [15]. Samples were introduced with a $1 \mu \mathrm{L}$ splitless injection and separation was achieved using a HP-5 capillary column (30 m x $0.32 \mathrm{~mm} ; 0.25 \mu \mathrm{m}$ film thickness) (J\&W Scientific, Folsom, USA). Amounts of eluted pesticides from each sampler were calculated from detected pesticide peaks, and divided by the number of days of deployment to give TWA amounts of absorbed pesticides by the sampler per day.

One litter of grab samples of river water were also collected at sites A-C on the retrieval of the passive samplers in December 2013. They were extracted by solid phase extraction with SDB-XC disks, eluted with acetone, and analyzed in the same way as for the passive samples.

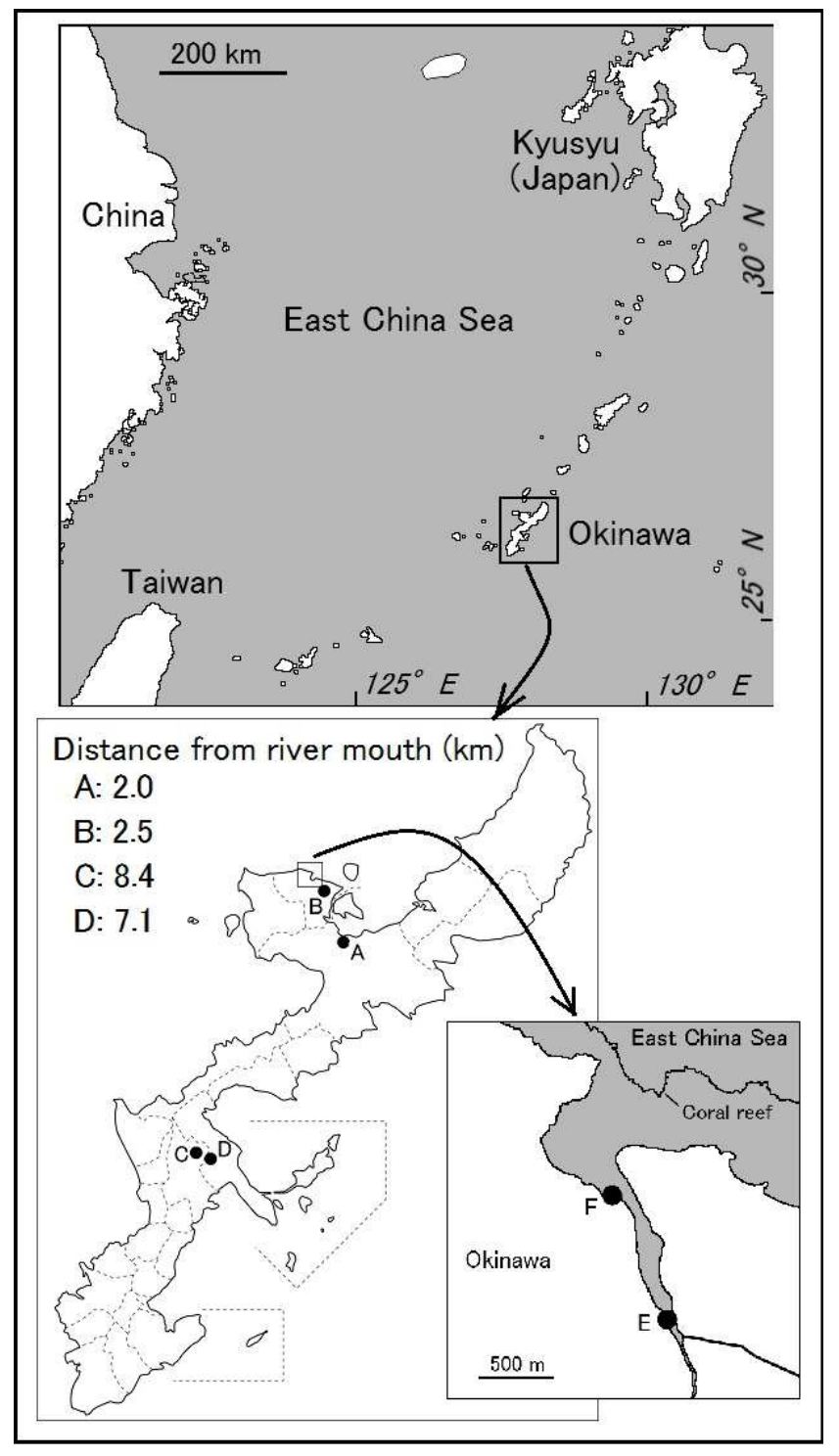

Figure 1. Location of the sampling sites. 
Table 1. Pesticides analyzed in the present study, and their consumptions [12] in Okinawa Prefecture in 2011 fiscal year.

\begin{tabular}{lllllllll}
\hline Insecticides & $\begin{array}{l}\text { No. in } \\
\text { Fig. } 2\end{array}$ & $\begin{array}{l}\text { Consumption } \\
\text { (ton) }\end{array}$ & Fungicides & $\begin{array}{l}\text { No. in } \\
\text { Fig. } 2\end{array}$ & $\begin{array}{l}\text { Consumption } \\
\text { (ton) }\end{array}$ & Herbicides & $\begin{array}{l}\text { No. in } \\
\text { Fig.2 }\end{array}$ & $\begin{array}{l}\text { Consumption } \\
\text { (ton) }\end{array}$ \\
\hline MEP & 1 & 19 & Metalaxyl & 16 & 26 & Pendimethalin & 23 & 1.5 \\
Benfuracarb & 2 & 6.1 & TPN & 17 & 5.9 & Metribuzin & 24 & 0.90 \\
BPMC & 3 & 5.9 & Tolclofos-methyl & 18 & 5.1 & Esprocarb & 25 & 0.31 \\
Prothiofos & 4 & 5.0 & Captan & 19 & 3.1 & Mefenacet & 26 & 0.12 \\
Carbosulfan & 5 & 4.5 & Triflumizol & 20 & 1.5 & Pretalachlor & 27 & 0.09 \\
Carbofuran & 6 & & IBP & 21 & 1.4 & Dimethametryn & 28 & 0.01 \\
Ethylthiometon & 7 & 4.3 & Procymidone & 22 & 1.3 & & \\
Isoxathion & 8 & 2.4 & & & & & \\
Diazinon & 9 & 2.1 & & & & & \\
Malathion & 10 & 1.9 & & & & & \\
DMTP & 11 & 1.3 & & & & & \\
EPN & 12 & 1.3 & & & & & \\
DEP & 13 & 1.2 & & & & & \\
MPP & 14 & 1.0 & & & & & \\
PAP & 15 & 0.67 & & & & & \\
\hline
\end{tabular}

*Carbofuran is a metabolite of carbosulfan.

\section{Results and Discussion}

One to 12 kinds of pesticides were detected from all the samplers deployed at sites A-D with the maximum amount of $260 \mathrm{ng} \mathrm{day}^{-1}$ for EPN from a sampler at site C (Fig.3). Only 8 among the all analyzed compounds were not detected from any of the samplers. The detected compounds and their amounts fluctuated widely at each sampling occasion. The analyses of the grab water samples detected much less compounds in comparison with the passive samples from the same sites. These results suggest that passive sampling could figure out the pollutions of this island more in detail than grab sampling.

The samplers at all these sites absorbed carbosulfan, carbofuran, and tolclofos-methyl in November, and procymidone in December. On the other hand, EPN and PAP were detected in November only at sites C and D in the northern area of the island, whereas BPMC was detected in September only at sites A and B in the central area, possibly reflecting different pesticide applications in each region. These features of pollution suggest that the fluctuation of the amounts should be attributed to the temporal discharges of pesticides from the farms caused by the spraying practices of the pesticides by the farmers and/or flushing by rainfall events during the deployment terms.

According to the calibration by Gunold et al. [16], the sampling rate of Chemcatcher ${ }^{\circledR}$ with SDB-XC disk without diffusion-limiting membrane for semi-polar pesticides is 0.12-0.44 $\mathrm{L} \mathrm{day}^{-1}$. It is also reported that the use of a membrane decreased the sampling rate for atrazine by a factor of 10 [15]. Based on these data, the TWA concentrations of the pesticides detected by the samplers in the present study are estimated as several micrograms per litter in the river waters. Thus, it is probable that the concentration of EPN at site $\mathrm{C}$ in November was exceeding the guideline value of $6 \mu \mathrm{g} \mathrm{L}^{-1}$ for EPN in water environments by Japanese Ministry of the Environment.

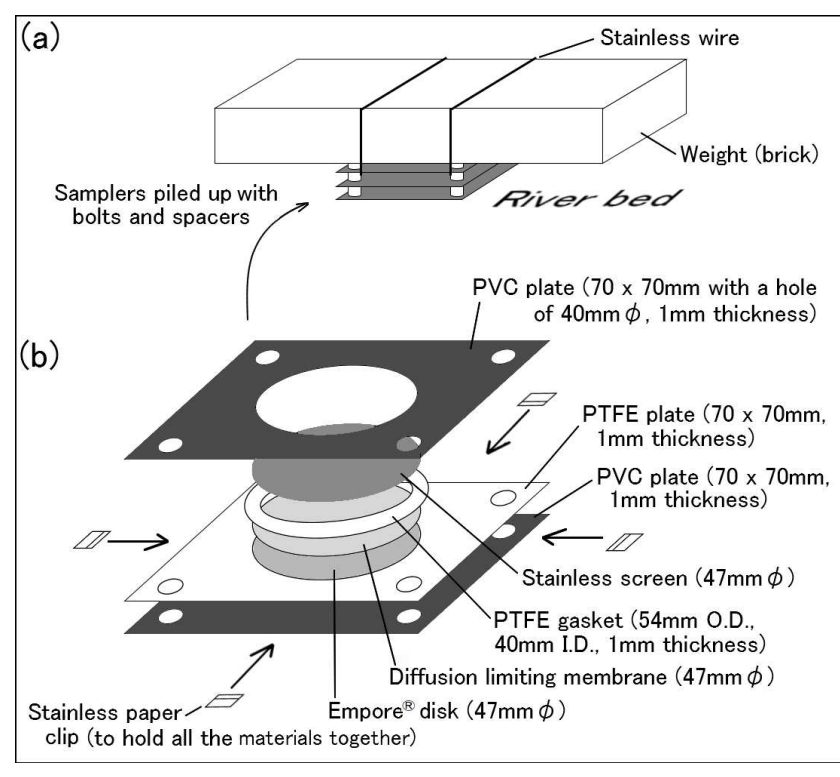

Figure 2. Installation (a) and structure (b) of passive samplers.

Sheikh et al. [5] detected $753 \mathrm{ng} \mathrm{L}^{-1}$ as maximum concentration of diuron, a herbicide commonly used in Japan, in a grab sample of river water from Ishigaki, another island of the Southwest Islands. They also detected $50 \mathrm{ng} \mathrm{L}^{-1}$ of diuron at another site about $4 \mathrm{~km}$ downstream of the same river near the coast. This reduction for about one order in concentration may be attributed to the dilution and/or decomposition of the compound in river water. In the present study, three pesticides, including procymidone with the largest amount of $2.8 \mathrm{ng} \mathrm{day}^{-1}$, were detected at site $\mathrm{E}$ which is located at the inner part of an estuary of a river. As many of the pesticide amounts absorbed by the samplers at the river sites on this island were some dozens of ng day ${ }^{-1}$, the reduced concentrations detected in the estuary were in harmony with the results in Ishigaki. Further, $0.1 \mathrm{ng} \mathrm{day}^{-1}$ of procymidone was also detected at site $\mathrm{F}$ in the middle of the same estuary where the river water is largely diluted with sea water. This amount of pesticide corresponds to a TWA concentration in water with the order of several ng 
$\mathrm{L}^{-1}$, which is in the same order of the concentrations of herbicides detected in inshore reef and river mouth sites of the Great Barrier Reef [17]. As the chemicals applied on the farms and discharged into fresh water run off to the coast within a relatively short time on the small islands, they potentially approach the coral reefs without enough time and contacts with river beds necessary for degradation and/or absorption. Also the small water catchments of the rivers on the islands can provide a limited amount of water for dilution before the pesticides are discharged into the coastal seawater.
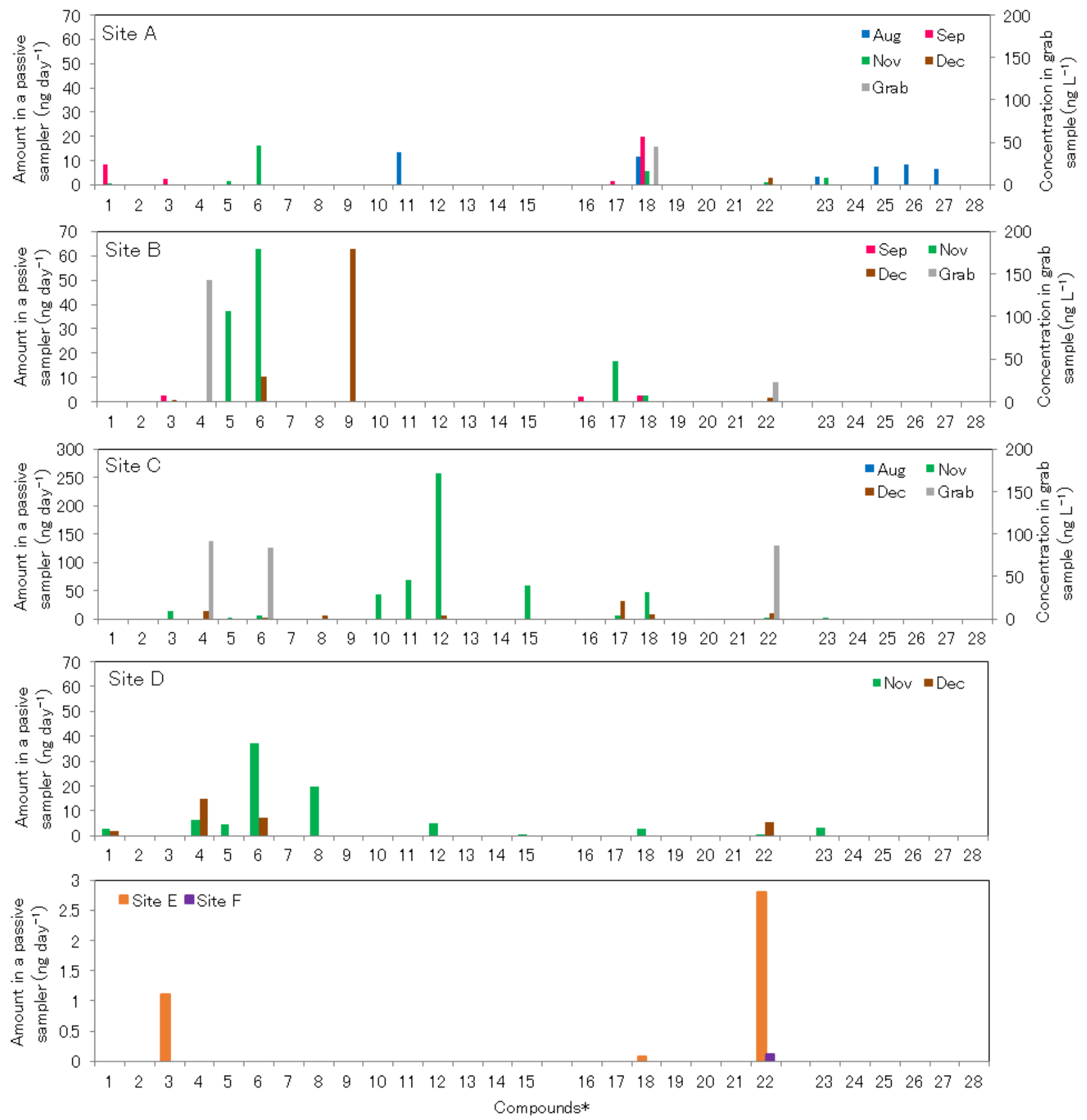

Figure 3. Amounts of pesticides absorbed by passive samplers and concentrations in grab samples (*: compounds are indicated with the numbers corresponding to Table 1).

\section{Conclusions}

The results of passive samplings revealed that a variety of pesticides are discharged through rivers into coastal seawater around the Okinawa Island, where the conservation of aquatic environments is important to maintain the unique ecosystems in the enclosed moats and on the fringing reefs. Intensive agricultural practices such as flower cultivations may lead to considerable discharges of chemicals into coastal water even in the case of small islands. Although the concentrations of pesticides detected from the estuary in the present study were low, chronic environmental impacts and higher levels of 
temporal pollutions by occasional discharges are concerned. The importance of continuous efforts to improve the understandings on the sources and the distribution of seawater pollutions around these islands is emphasized.

\section{Acknowledgements}

This study was supported by Grant-in-Aid for Scientific Research of the Japan Society for the Promotion of Science (Grant No. 25340062).

\section{References}

[1] C. M. Roberts, C. J. McClean, J. E. N. Veron, J. P. Hawkins, G. R. Allen, D. E. McAllister, C. G. Mittermeier, F. W. Schueler, M. Spalding, F. Wells, C. Vynne and T. B. Werner, Marine biodiversity hotspots and conservation priorities for tropical reefs, Science, 295(5558), 2002, 1280-1284.

[2] Y. Tashiro and T. Taniyama, Pesticide contamination in groundwater on Okinoerabu Island, an intensive agricultural district in Japan (in Japanese), Jpn. J. Crop. Sci., 65, 1996, $77-86$

[3] S. T. Imo, M. A. Sheikh, K. Sawano, H. Fujimura and T. Oomori, Distribution and possible impacts of toxic organic pollutants on coral reef ecosystems around Okinawa Island, Japan, Pacific Science, 62(3), 2008, 317-326.

[4] Y. Kitada, H. Kawahata, A. Suzuki and T. Oomori, Distribution of pesticides and bisphenol A in sediments collected from rivers adjacent to coral reefs, Chemosphere, 71, 2008, 2082-2090.

[5] M.A. Sheikh, T. Oomori, H. Fujimura, T. Higuchi, T. Imo, A. Akamatsu, T. Miyagi, T. Yokota and S. Yasumura, Distribution and potential effects of novel antifouling herbicide diuron on coral reefs, in Herbicides - Environmental Impact Studies and Management Approaches, Dr. Ruben Alvarez-Fernandez (Ed.), ISBN: 978-953-307-892-2, 2012, InTech,

[6] Y. Tashiro and Y. Kameda, Concentration of organic sun-blocking agents in seawater of beaches and coral reefs of Okinawa Island, Japan, Marine Pollution Bulletin, 77, 2013, 333-340.

[7] J. Kingston, R. Greenwood, G. Mills, G. Morrison and L. Pesson, Development of a novel passive sampling system for the time averaged measurement of a range of organic pollutants in aquatic environments, Journal of Environmental Monitoring, 2, 2000, 487-495.

[8] R. B. Schäfer, A. Paschke, B. Vrana, R. Mueller and M. Liess, Performance of the Chemcatchers passive sampler when used to monitor 10 polar and semi-polar pesticides in 16 Central European streams, and comparison with two other sampling methods, Water Research, 42, 2008, 2707 - 2717.

[9] M. Shaw, M. J. Furnas, K. Fabricius, D. Haynes, S. Carter, G. Eaglesham and J. F. Mueller, Monitoring pesticides in the Great Barrier Reef, Marine Pollution Bulletin, 60, 2010, 113-122.

[10] F. Sánchez-Bayo, R. V. Hyne, G. Kibria and P. Doble, Calibration and field application of Chemcatcher passive samplers for detecting amitrole residues in agricultural drain waters, Bull. Environ. Contam. Toxicol., 90, 2013, 635-639.

[11] F. Sánchez-Bayo and R. V. Hyne, Detection and analysis of neonicotinoids in river waters - Development of a passive sampler for three commonly used insecticides, Chemosphere, 99, 2014, 143-151.

[12] Japan Plant Protection Association, "Noyaku Yoran (Pesticide Handbook) 2013" (in Japanese), 2013, JPPA.

[13] Japanese Ministry of the Environment, "Interim manual for investigations on endocrine disrupting compounds" (in Japanese), 1998, JME.

[14] E. L. M. Vermeirssen, C. Dietschweiler, B. I. Escher, J. van der Voet and J. Hollender, Uptake and release kinetics of 22 polar organic chemicals in the Chemcatcher passive sampler, Anal. Bioanal. Chem., 405, 2013, 5225-5236.

[15] A. T. K. Tran, R. V. Hyne and P Doble, Calibration of a passive sampling device for time-integrated sampling of hydrophilic herbicides in aquatic environments, Environ. Toxicol. Chem., 26, 2007, 435-443.

[16] R. Gunold, R. B. Schäfer, A. Paschke, G. Schüürmann and M. Liess, Calibration of the Chemcatcher passive sampler for monitoring selected polar and semi-polar pesticides in surface water, Environmental Pollution, 155, 2008, 52-60.

[17] M. Shaw and J. F. Mueller, Preliminary evaluation of the occurrence of herbicides and PAHs in the Wet Tropics region of the Great Barrier Reef, Australia, using passive samplers, Marine Pollution Bulletin, 51, 2005, 876-881. 